\title{
Electrically Conductive Composite of Polyaniline-Aramid and Its Application as a Cathode Material for Secondary Battery
}

\author{
Keiko Koga, Sumio Yamasaki, Koichiro NARImatsu, \\ and Motowo TAKAYANAGI \\ Department of Industrial Chemistry, Faculty of Engineering, \\ Kyushu Sangyo University, \\ Matsukadai 2-3-1, Higashi-ku, Fukuoka 813, Japan
}

(Received April 5, 1989)

\begin{abstract}
An electroconductive composite of polyaniline and poly( $p$-phenylene terephthalamide) (PPTA) was prepared to provide a light-weight, self-supporting, conductive polymeric film. The electropolymerization of aniline was conducted in acidic water on the electrode covered with the PPTA film. The composite is a flexible self-supporting film having a tensile modulus of $2 \mathrm{GPa}$ and tensile strength of $160 \mathrm{MPa}$. The results of cyclic voltammetry and battery test on the composite electrode revealed that the electrochemical activities of the composite are almost the same as those of the polyaniline single film.
\end{abstract}

KEY WORDS Poly( $p$-phenylene terephthalamide) / Polyaniline /

Conductive Composite / Secondary Battery /

Polyaniline is a promising conductive polymers because of its facility of synthesis and chemical stability. Its applications such as secondary battery ${ }^{1-3}$ and display ${ }^{4}$ have been investigated extensively. A film of polyaniline is electrochemically polymerized in acidic water, ${ }^{5}$ but the film is mechanically weak like other electroconductive polymers. In order to improve these mechanical properties, the composite formation has been attempted using elecyroconductive polymers and inert host polymers. Among them, the most successful method to form the composite was found in the electropolymerization of conductive polymer on the electrode covered with the insulating polymer. For example, polypyrrole/ poly(vinyl chloride) (PVC), ${ }^{6,7}$ polypyrrole/ poly(vinyl alcohol) ${ }^{8}$ polythiophene $/ \mathrm{PVC}^{9}$ etc. have been prepared by this method. As for the polyaniline, there are only a few reports on the composite such as polyaniline/ poly(methyl methacrylate). ${ }^{10}$ This composite is a thin film of $200 \mathrm{~nm}$ thickness and not selfsupporting.

Recently we reported the mechanically strong conductive composite of polypyrrole and $\operatorname{poly}(p$-phenylene terephthalamide) (PPTA) formed by the above method. ${ }^{11}$ PPTA is well-known as the molecule used for Kevlar fiber of du Pont company having ultrahigh strength and ultrahigh modulus. The PPTA film was found by us to be prepared by the electrodposition of PPTA polyanion dissolved in dimethylsulfoxide (DMSO). ${ }^{12}$ As-electrodeposited PPTA film is in a state of gel. The PPTA film obtained by the appropriate treatment is in a solvated state with DMSO and has coarse texture, which enables us to form the composite with conductive polymers. ${ }^{11}$ In this paper, we report the composite of polyaniline and PPTA prepared by the electropolymerization of aniline on the electrode covered with the electrodeposited PPTA film and also describe the performance 
of the composite as a cathode material for a secondary battery compared with that of polyaniline single film.

\section{EXPERIMENTAL}

A PPTA-coated electrode was formed as follows. PPTA $\left(M_{v}=50,000\right.$, supplied by Asahi Chemical Industry Company) was converted to the solution of PPTA polyanion in DMSO by the procedure of Takayanagi and Katayose. ${ }^{13}$ The electrolysis of the solution ( $2.5 \mathrm{~g}$ of PPTA in 11 of DMSO) was carried out galvanostatically under the condition of $2.5 \mathrm{~mA} \mathrm{~cm}^{-2}$ for $7 \mathrm{~min}$ by use of the same equipment as reported previously. ${ }^{12} \mathrm{~A}$ sheet of electrodeposited PPTA gel containing DMSO was stripped from the electrode and immersed in $1 \mathrm{~N}$ aqueous $\mathrm{HCl}$. The gel was dried on an indium-tin-oxide (ITO) glass plate (supplied by Nippon Sheet Glass Company) at room temperature for one day to provide a PPTA-coated electrode. The thickness of the PPTA film was usually $17 \mu \mathrm{m}$. It was varied by regulating the time of electrolysis to examine its dependence on the electrochemical response of the polyaniline-PPTA composite. Aniline was electrochemically polymerized onto PPTA-coated electrode $(1 \mathrm{~cm}$ wide and $3 \mathrm{~cm}$ long) in a one-compartment, three-electrode cell using a platinum counter electrode and a potassium chloride-saturated calomel electrode (SCE) for the reference electrode. The electrolytic solution was $0.5 \mathrm{M}$ aniline and $1 \mathrm{M}$ hydrogen perchlorate aqueous solution. The polymerization was conducted potentiostatically at a voltage of $+0.8 \mathrm{~V} v s$. SCE until a certain amount of charge controlled by a coulomb meter (Hokuto Electric, HF 201) was consumed. Polyaniline single film for comparison with the composite was prepared on an ITO glass plate under the same conditons. After the electropolymerization, the electrode was rinsed with water and dried at room temperature. The sample film was either removed from the electrode for conductivity measurements, scanning electron microscope observation and tensile tests or left on the electrode for electrochemical characterizations and battery tests. The conductivity was measured using a standard four-probe technique. Scanning electron micrographs were taken with a Hitachi S-510 Scanning Electron Microscope (SEM). A tensile test was carrried out by Tensilon STM-50BT (Orientec). The cyclic voltammetry was performed in $1 \mathrm{M} \mathrm{HClO}_{4}$ aqueous solution using a dual potentio-galvanostat (Nikko Keisoku, DPGS-1) equipped with a potential sweeper (Nikko Keisoku, NPS-2). The sweep rate was $20 \mathrm{mVs}^{-1}$ and the voltage window was $-0.3 \mathrm{~V}$ up to $+1.0 \mathrm{~V}$ vs. SCE. A battery cell was constructed with polyaniline-PPTA/ITO or polyaniline/ITO as a cathode and zinc as an anode with a battery solution of aqueous $0.5 \mathrm{M} \mathrm{ZnSO}$. The distance of the two electode from each other was $20 \mathrm{~mm}$. The amount of charge consumed during the polymerization of aniline $\left(Q_{\mathrm{p}}\right)$ was $1 \mathrm{C} \mathrm{cm}^{-2}$ for both the compostite and the polyaniline single film. The charge-discharge measurments were carried out at a constant current density of $50 \mu \mathrm{Acm}^{-2}$ using a battery charge/discharge system, HJ-201B (Hokuto Electric). For the charge-discharge cycling, the cut-off valtage was $0.9 \mathrm{~V}$ up to $1.4 \mathrm{~V}$. The cycle test was conducted in a nitrogen atmosphere.

\section{RESULTS AND DISCUSSION}

\section{Cyclic Voltammetry}

Figure 1 shows the cyclic voltammograms of the polyaniline-PPTA composite (curve $a$ ) and the polyaniline single film (curve $b$ ) in $1 \mathrm{M}$ $\mathrm{HClO}_{4} . \quad Q_{\mathrm{p}}$ for the both samples was $0.1 \mathrm{C} \mathrm{cm}^{-2}$. Both voltammograms show two pairs of redox current peaks. The anodic peaks lie at $+0.3 \mathrm{~V}$ and $+0.8 \mathrm{~V}$ vs. SCE and the cathodic peaks lie at $-0.1 \mathrm{~V}$ and $+0.5 \mathrm{~V} v s$. SCE. These redox current peaks of the polyaniline are similar to those reported in the literature, ${ }^{4}$ but the peaks obtained using an ITO electrode (this case) are broad compared 


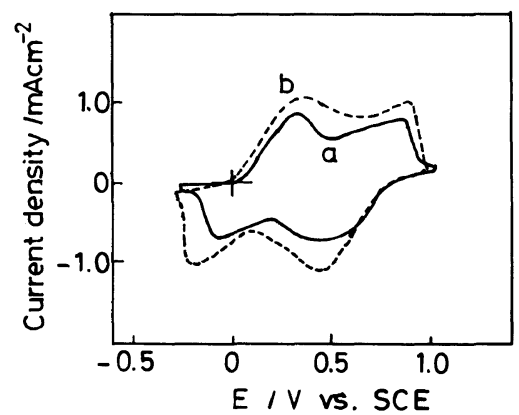

Figure 1. Cyclic voltammograms of $(a)$ polyanilinePPTA composite and $(b)$ polyaniline single film in $1.0 \mathrm{M}$ $\mathrm{HClO}_{4}: Q_{\mathrm{p}}=0.1 \mathrm{C} \mathrm{cm}^{-2}$; sweep rate, $20 \mathrm{mV} \mathrm{s}^{-1}$.

with the peaks using a Pt electrode. The apparent elctrochemical activity of the composite is slightly poor compared with the polyaniline single film. Two processes of the redox reactions were proposed by several research groups. ${ }^{14-17}$ One process is associated with the proton elimination-addition reaction and the other with the anion doping-undoping reaction. Each redox peak revealed in the cyclic voltammogram has not been exactly assigned to the redox reaction so far. However, the same redox reactions of the polyaniline seem to occur in the composite.

In general, the relation between the peak current value of the redox current, $i_{\mathrm{p}}$, and the potential sweep rate, $V_{\mathrm{s}}$, is represented by $i_{\mathrm{p}}=k V_{\mathrm{s}}^{x}$ and, consequently, a plot of $\log i_{\mathrm{p}}$ against $\log V_{\mathrm{s}}$ is found to be linear with a slope of $x$. If the rate-determining step in the redox reaction is the charge transfer at the electrode, $x$ is 1 , and if the diffusion process, $x$ is 0.5 . Figure 2 shows the relation between the thickness of the PPTA film and the $x$ value obtained by the plots of the logarithm of the anodic peak current and the cathodic peak current in the lower potential side (see Figure 1) against $\log V_{s}$. Similar plots were obtained for higher potential peaks. $Q_{\mathrm{p}}$ for all the composites used here is $0.01 \mathrm{C} \mathrm{cm}^{-2}$. Under this polymerization condition, the polyaniline grows only near the electrode side of the PPTA film. The $x$ value of 0.75 is approximately constant independent of

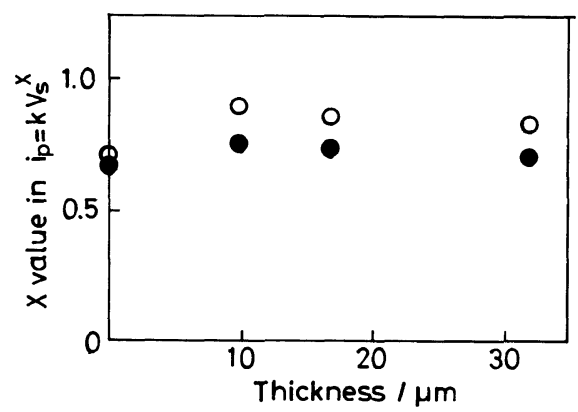

Figure 2. Relationship between $x$ value and thickness of the PPTA film: anodic peak current; $\bigcirc$, cathodic peak current.

the thickness of the PPTA films. The $x$ value of the composite is rather larger than that of polyaniline single film. Judging from the $x$ values, the $\mathrm{ClO}_{4}^{-}$ion as a dopant may possibly diffuse more easily through the texture of PPTA of the composite based on the assumption that the charge-transfer process at the electrode takes place in the same manner between the single and the composite films.

\section{Morphology}

Figure 3 shows SEM photographs of the polyaniline-PPTA composite $(a-c)$ and the PPTA single film (d). (a) and (b) are the surface appearances at the solution side of $Q_{\mathrm{p}}=7 \mathrm{C} \mathrm{cm}^{-2}$ and $10 \mathrm{C} \mathrm{cm}^{-2}$, respectively. (c) and (d) are the fractured surfaces of the composite $\left(Q_{\mathrm{p}}=10 \mathrm{C} \mathrm{cm}^{-2}\right)$ and the PPTA single film, respectively. In the process of the composite formation, polymerization of aniline occurs initially at the electrode side and grows toward the surface of the PPTA film. In Figure 3(a), a fibril of polyaniline is found to grow from the PPTA film surface. The surface of the composite is entirely covered with the fibrils with increase of $Q_{\mathrm{p}}$ (Figure 3 (b)). At $Q_{\mathrm{p}}=4 \sim 5 \mathrm{C} \mathrm{cm}^{-2}$, polyaniline grows just to reach the PPTA film surface. The PPTA film prepared by the electrodeposition has a layerstructure as clearly seen in Figure 3 (d). On the other hand, a uniformly fine structure is found in the whole fractured surface of the com- 


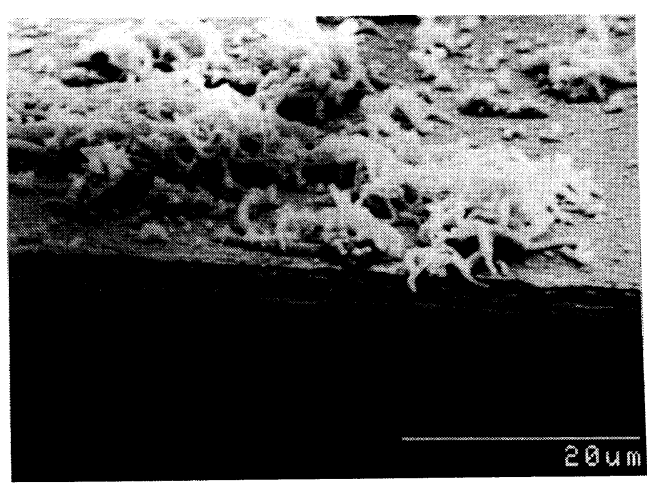

(a)

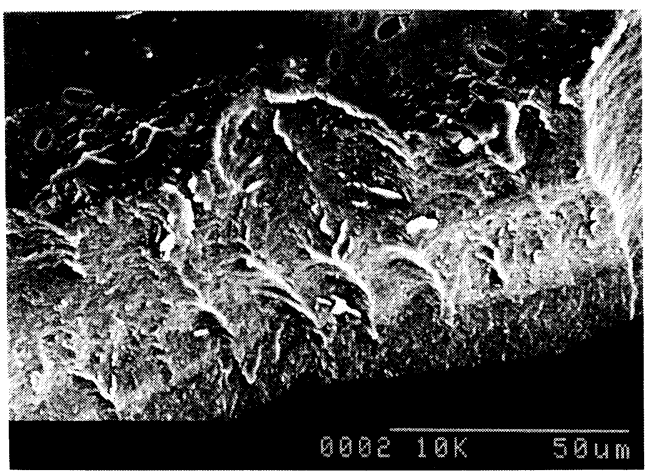

(c)

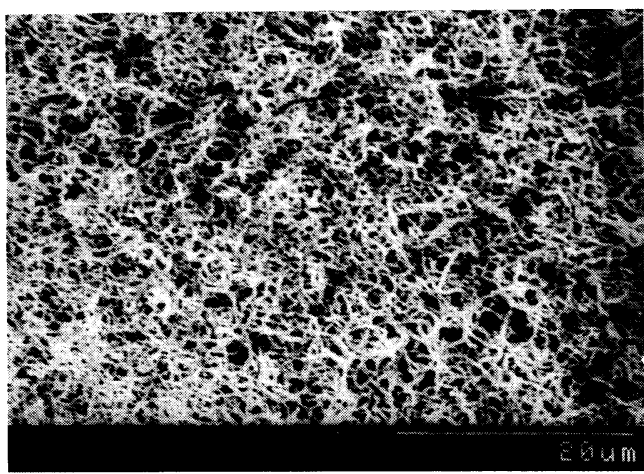

(b)

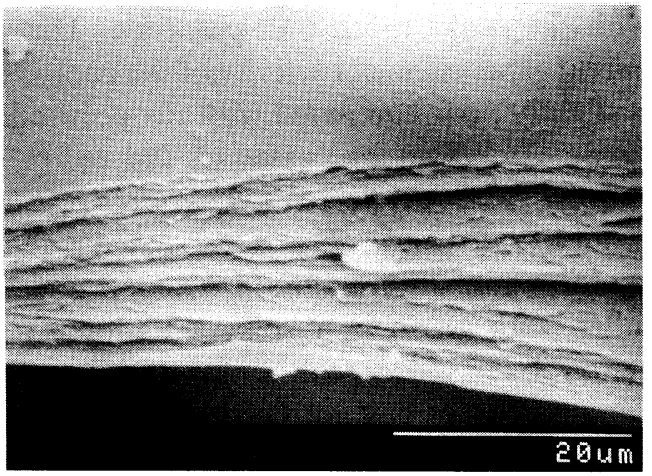

(d)

Figure 3. SEM photographs of surface appearances at the solution side of polyaniline-PPTA composite of (a) $Q_{\mathrm{p}}=7 \mathrm{C} \mathrm{cm}^{-2}$ and (b) $Q_{\mathrm{p}}=10 \mathrm{C} \mathrm{cm}^{-2}$, and the fractured surfaces of (c) the composite of $Q_{\mathrm{p}}=$ $10 \mathrm{C} \mathrm{cm}^{-2}$ and (d) PPTA single film.

posite, which suggests that the regions of polyaniline and PPTA interpenetrate mutually. In order to study the morphology of the polyaniline more in detail, the etching of the PPTA was tried by the "NaH-DMSO" reagent. This method was successful in the case of polypyrrole-PPTA composite. ${ }^{11}$ However, both polyaniline and PPTA were dissolved in the reagent and the morphology of the polyaniline was not observed separately. It should be noted that polyaniline dissolved in the "NaH-DMSO" reagent because it is generally insoluble in organic solvents except concentrated sulfuric acid. ${ }^{18}$ The morphology of polypyrrole in the polypyrrole-PPTA com- posite depends on the preparetion procedure of PPTA film, i.e., the procedure by washing the PPTA gel as-electrodeposited with aqueous $\mathrm{HCl}^{19}$ or with acetonitrile. ${ }^{11}$ The PPTA film obtained by washing with aqueous $\mathrm{HCl}$ is highly crystalline and may be porous. Therefore, polyaniline in the composite is incorporated in a state of fine network into the PPTA film as found in the polypyrrole-PPTA composite. ${ }^{19}$ The porous structure of the PPTA film also contributes to good electrochemical responsibility of the composite film. 
Table I. Mechanical properties of polyaniline-PPTA composite and PPTA single film

\begin{tabular}{|c|c|c|c|c|}
\hline \multirow{2}{*}{ Sample } & $Q_{\mathrm{p}}{ }^{\mathrm{a}}$ & Tensile modulus & Tensile strength & Elongation at break \\
\hline & $\mathrm{C} \mathrm{cm}^{-2}$ & $\mathrm{GPa}$ & $\mathrm{MPa}$ & $\%$ \\
\hline PPTA & - & 4.4 & 124 & 4.3 \\
\hline Polyaniline-PPTA & 1.0 & 3.3 & 119 & 5.3 \\
\hline Polyaniline-PPTA & 2.5 & 2.4 & 125 & 7.3 \\
\hline Polyaniline-PPTA & 5.0 & 2.1 & 159 & 12.0 \\
\hline
\end{tabular}

${ }^{a} Q_{\mathrm{p}}$ is the amount of charge consumed at the polymerization of aniline.

\section{Mechanical Properties}

Table I shows the results of tensile tests for the composites of various $Q_{\mathrm{p}}$ and the PPTA single film. The tensile modulus of the composite decreases with increase of $Q_{\mathrm{p}}$. The tensile strength and elongation at break of the composite increase with increase of $Q_{\mathrm{p}}$. The tensile modulus and the tensile strength are 2 $\mathrm{GPa}$ and $160 \mathrm{MPa}$, respectively, for the composite of $Q_{\mathrm{p}}=5 \mathrm{C} \mathrm{cm}^{-2}$ in which polyaniline is incorporated throughout the PPTA film. On the other hand, the polyaniline single film deposited on the electrode is too fragile to measure its mechanical properties. Although the mechanical properties of the polyaniline single film is not known, the tendency revealed in Table I suggests that the polyaniline is softer than the PPTA film. The conductivity of the composite is $5 \mathrm{~S} \mathrm{~cm}^{-1}$ for the sample in which polyaniline is incorporated entirely. Thus, the mechanical properties of the polyaniline largely improved by the composite formation without reduction in electrochemical activity. Attention should be called to the fact that the PPTA film used here is less hard and strong than the one completely dried and/or annealed. ${ }^{12}$

\section{Battery Tests}

Figure 4 shows the charge-discharge curves for the $\mathrm{Zn}$ /polyaniline-PPTA battery (curve $a$ ) and the $\mathrm{Zn}$ /polyaniline battery (curve $b$ ). As the cell voltage exceeds $1.5 \mathrm{~V}$, the discharge capacities of the both cells decrease abruptly. About $100 \%$ coulombic effciency is obtained

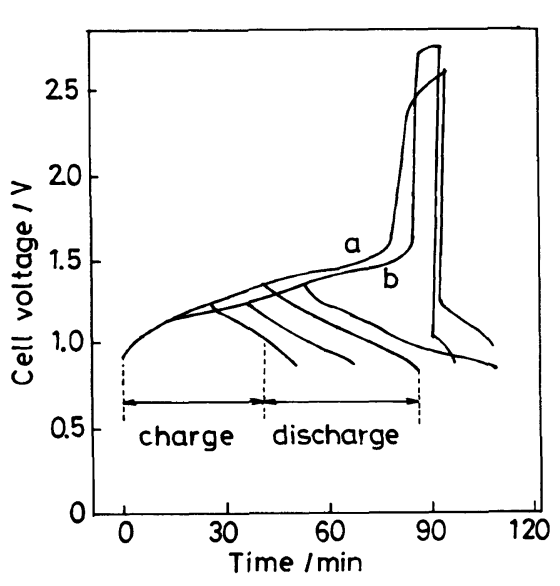

Figure 4. Charge-discharge curves for (a) $\mathrm{Zn} /$ polyaniline-PPTA and $(b) \mathrm{Zn}$ /polyaniline cells: Charge and discharge current, $50 \mu \mathrm{A} \mathrm{cm}^{-2}$.

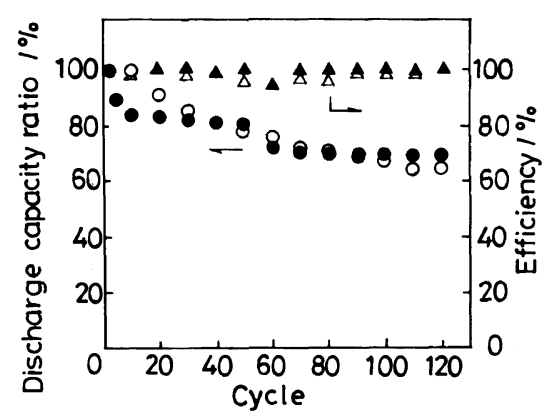

Figure 5. Discharge capacity ratio and coulombic efficiency for the repetition of charge and discharge for polyaniline-PPTA (filled marks) and polyaniline (open marks) electrodes: Charge and discharge current, $50 \mu \mathrm{A} \mathrm{cm}^{-2}$; electrolyte, $0.5 \mathrm{M} \mathrm{ZnSO}_{4}$.

for both cells when the cell voltage is between $0.9 \mathrm{~V}$ and $1.4 \mathrm{~V}$. The charge capacity of the $\mathrm{Zn}$ /polyaniline-PPTA battery is about $90 \%$ 
that of the $\mathrm{Zn} /$ polyaniline battery. The other electrolytes such as $\mathrm{Zn}\left(\mathrm{ClO}_{4}\right)_{2}$ and $\mathrm{ZnCl}_{2}$ were examined as a battery solution, and the charge capacity of the battery in both cases was lower than that of the battery using $\mathrm{ZnSO}_{4}$ solution. Reactions in both cells during the charge and discharge proceeses are represented by

$$
\begin{aligned}
& \left(\mathrm{C}_{6} \mathrm{H}_{5} \mathrm{~N}\right)_{\mathrm{n}}+\mathrm{yZnSO}_{4} \\
& \quad \rightleftharpoons\left(\mathrm{C}_{6} \mathrm{H}_{5} \mathrm{~N}\right)_{\mathrm{n}}{ }^{+2 \mathrm{y}}\left(\mathrm{SO}_{4}\right)_{\mathrm{y}}+\mathrm{yZn}
\end{aligned}
$$

Figure 5 shows the results of cycle test for the $\mathrm{Zn}$ /polyaniline-PPTA battery (filled marks) ant $\mathrm{Zn}$ /polyaniline battery (open marks). In this figure, the discharge capacity is represented as the ratio of it to the first discharge capacity. The coulombic efficiency is almost $100 \%$ even at the 120 th cycles for both batteres with the cell voltage set up between $0.9 \mathrm{~V}$ and $1.4 \mathrm{~V}$. The discharge capacity falls to $70 \%$ at the 120 th cycles of chargedischarge repetition for both batteries. The performance of te $\mathrm{Zn}$ /polyaniline-PPTA battery is almost the same as the $\mathrm{Zn}$ /polyaniline battery.

\section{CONCLUSIONS}

An electroconductive composite of polyaniline and poly( $p$-phenylene terephthalamide) (PPTA) was prepared by the electropolymerization of aniline in the matrix film of PPTA. The polyaniline-PPTA composite has improved mechanical properties and its electrochemical activity is almost the same as polyaniline single film. The flexible self-supporting film of the composite with light weight broadens the scope of its application.

\section{REFERENCES}

1. A. G. MacDiarmid, S.-L. Mu, N. L. D. Somasiri, and W. Wu, Mol. Cryst. Liq. Cryst., 121, 187 (1985).

2. A. Kitani, M. Kaya, Y. Hiromoto, and K. Sasaki, Denki Kagaku, 53, 592 (1985).

3. A. Kitani, M. Kaya, and K. Sasaki, J. Electrochem. Soc., 133, 1069 (1986).

4. T. Kobayashi, H. Yoneyama, and H. Tamura, J. Electroanal. Chem., 161, 419 (1984).

5. A. F. Diaz and J. A. Logan, J. Electroanal. Chem., 111, 111 (1980).

6. O. Niwa, M. Hikita, and T. Tamamura, Makromol. Chem., Rapid Commun., 6, 375 (1985).

7. M.-A. DePaoli, R. J. Waltman, A. F. Diaz, and J. Bargon, J. Polym. Sci., Polym. Chem. Ed., 23, 1687 (1985).

8. S. E. Linsey and G. B. Street, Synth. Mat., 10, 67 (1984/85).

9. O. Niwa and T. Tamamura, Synth. Met., 20, 235 (1987).

10. A. F. Diaz, Makromol. Chem., Makromol. Symp., 8, 17 (1987).

11. K. Koga, T. Iino, S. Ueta, and M. Takayanagi, Polym. J., 21, 303 (1989).

12. K. Koga, S. Ueta, and M. Takayanagi, Polym. J., 20, 639 (1988).

13. M. Takayanagi and T. Katayose, J. Polym. Sci., Polym. Chem. Ed., 19, 1133 (1981).

14. A. Kitani, J. Izumi, J. Yano, Y. Hiromoto, and K. Sasaki, Bull. Chem. Soc. Jpn., 57, 2254 (1984).

15. T. Kobayashi, H. Yoneyama, and H. Tamura, $J$. Electroanal. Chem., 177, 281 (1984).

16. E. M. Genies, A. A. Syed, and C. Tsintavis, Mol. Cryst. Liq. Cryst., 121, 181 (1985).

17. A. G. MacDiarmid, J. C. Chiang, M. Halpern, and W. Wu, Mol. Cryst. Liq. Cryst., 121, 173 (1985).

18. A. Andreatta, Y. Cao, J. C. Chiang, A. J. Heeger, and P. Smith, Synth. Met., 26, 383 (1988).

19. K. Koga, T. Iino, S. Ueta, and M. Takayanagi, Polym. J., 499 (1989). 